\title{
Assessment of perceived stress and associated factors among pregnant women attending antenatal care at Arba Minch town governmental health institutions, southern Ethiopia, 2020
}

Abdi Deksisa Bane ( $\square$ abdideksisa4@gmail.com )

Arsi University https://orcid.org/0000-0003-1544-8791

Wubshet Estifanos Madebo

Arba Minch University college of Medicine amd health sciences

Gisila Endashaw

Medicines and Healthcare Products Regulatory Agency

Wondu Abera Bezabih

Arsi University College of Health Sciences

Kasahun Beyene Workie

Arsi University College of Health Sciences

Teklu Wosenyelehu

Mettu University

Research article

Keywords: Antenatal care, Ethiopia, Perceived stress, Pregnant women

Posted Date: October 20th, 2020

DOI: https://doi.org/10.21203/rs.3.rs-93496/v1

License: (c) (i) This work is licensed under a Creative Commons Attribution 4.0 International License.

Read Full License 
1 ASSESSMENT OF PERCEIVED STRESS AND ASSOCIATED

2 FACTORS AMONG PREGNANT WOMEN ATTENDING

3 ANTENATAL CARE AT ARBA MINCH TOWN GOVERNMENTAL

4 HEALTH INSTITUTIONS, SOUTHERN ETHIOPIA, 2020

5 AUTHORS: Abdi Deksisa ${ }^{1}$, Wubshet Estifanos ${ }^{2}$, Gisila Endashaw ${ }^{2}$, Wondu Abera ${ }^{1}$,

$6 \quad$ Kasahun Beyene ${ }^{1}$, Teklu Wosenyeleh ${ }^{3}$

$7{ }^{1}$ Department of Midwifery, Arsi University College of Medicine and Health Sciences,

8 Asella, Ethiopia

$9 \quad{ }^{2}$ School of Nursing, Arba Minch University College of Medicine and Health Sciences, Arba

10 Minch, Southern Ethiopia

$11{ }^{3}$ Department of Nursing, Mettu University Faculty of Public Health and Medical Science,

12 Mettu, western Ethiopia.

\section{Authors' email addresses}

14 AD: abdideksisa4@gmail.com

15 WE: estifo.wubshet@gmail.com

16 GE: Gisila.endashaw@ amu.edu.et

17 WA: wonduabera34@gmail.com

18 KB: kbeyene2016@gmail.com

19 TW: teklu.w2020@gmail.com 


\section{ABSTRACT}

25 Introduction: Perceived stress is a real or apparent inconsistency between environmental 26 demands required for survival and an individual's capacity to adjust to these requirements.

27 Worldwide stress is a very common problem. Females are at increased risk to develop 28 perceived stress in antepartum period. Stress during pregnancy has serious effects for both 29 the mother and newborn. However this problem doesn't get adequate attention during 30 antenatal care in Ethiopia.

31 Objective: To assess the magnitude of perceived stress and associated factors among 32 pregnant women attending antenatal care at Arba Minch town governmental health 33 institutions, Southern Ethiopia, 2020

34 Methods: Institution based cross-sectional study was employed from March 16 to April 23, 35 2020. A total of 460 mothers were included in the study. Systematic sampling was used to 36 select participants. Data were collected using structured pretested questionnaire, entered in to 37 epi data version 3.1 and then exported to SPSS version 25 for analysis. A bivariable and 38 multivariable logistic regression analysis was used to identify factors associated with 39 outcome variable and variables with $\mathrm{P}$ value $<0.05$ in the final model were considered 40 statistically significant.

41 Result: The magnitude of perceived stress during pregnancy was $23.1 \%$ (95\% CI; 19.1642 26.96\%). Multigravida $(\mathrm{AOR}=3.95,95 \% \mathrm{CI} ; 1.94-8.02)$, ANC initiation <16 weeks of 43 gestation $(\mathrm{AOR}=2.05,95 \% \mathrm{CI} ; 1.18-3.57)$, first trimester $(\mathrm{AOR}=3.03,95 \% \mathrm{CI} ; 1.34-$ $446.85)$ and unplanned pregnancy $(\mathrm{AOR}=4.32,95 \% \mathrm{CI} ; 2.55-7.31)$ were associated factors of 45 perceived stress during pregnancy.

46 Conclusion and recommendation: The findings showed that the magnitude of perceived 47 stress during pregnancy is high. Gravidity, time of ANC initiation, gestational age and status 48 of pregnancy were statistically significant associated factors of perceived stress during 49 pregnancy. Assessment and provision of emotional support for pregnant women is very 50 crucial.

51 Key words: Antenatal care, Ethiopia, Perceived stress, Pregnant women 


\section{Background}

53 Stress is an actual or perceived disparity between environmental demands required for 54 existence and an individual's capacity to adapt to these desires (1). Perceived stress during 55 pregnancy is defined as the disparity that a gravid lady feels when she cannot deal with 56 demands and worries (2). Pregnancy is considered stressful period that may provoke mental

57 illness and low level of perceived stress during pregnancy is good for the most favorable 58 development of the fetus, but if it goes beyond it may lead to long term effect on the fetus, 59 and change the development of the fetal nervous system (3).

60 Stress during pregnancy is a very common problem with nearly three-quarters of women 61 reported they had experienced at least one stressful event before the delivery of their child (4).

62 In Africa studies employed in democratic republic of Congo, Nigeria and Ghana show that the 63 prevalence of perceived stress during pregnancy was $57.1 \%, 46.7 \%$ and $28.6 \%$ respectively 64 (25-27). Similarly the study conducted in Ethiopia shows that the prevalence of perceived 65 stress during pregnancy is $11.6 \%(8)$.

66 Maternal stress can lead to increased rates of infant mortality, low birth weight and preterm 67 birth, which may have long term negative consequences for health and development of the 68 child (5). Studies have shown that women experiencing high stress are 1.5 to 3 times more 69 likely to experience preterm delivery than less stressed women (6). In order to prevent the 70 adverse outcome of stress during pregnancy for both the mother and fetus it is necessary to 71 screen and provide appropriate support during antenatal period by nurses, midwives, 72 obstetricians and mental health specialists (7). Even though majority of pregnant woman's 73 attend antenatal care which is recommended by world health organization current antenatal 74 care is ill-equipped to identify women suffering from high levels of stress or it does not assess 75 emotional status of pregnant mothers (8). In Ethiopia the antenatal care guideline does not 76 assess the emotional status of the pregnant mothers (9).

77 The study conducted in Ethiopia, Bale zone from November 2016 to April 2017 shows that;

78 among 386 pregnant mothers enrolled in the study the prevalence of perceived stress was $7911.6 \%$ (9). The magnitude of perceived stress was $12.4 \%$ in Iran, $6 \%$ in United states of 80 America, $7.33 \%$ in Ardabil Iran and 17.2\% in Canada (39,7,40,28). Other studies shows that 
81 the magnitude of stress in Saudi Arabia was 33.4\%, Ghana 50\%, Democratic republic of

82 Congo 57.1\%, Nepal 34\%, America 28\% and Ghana 28.6\% $(41,29,25,42,37,27)$.

83 Multiple investigations indicate that multigravida mothers are highly considered to have 84 perceived stress when compared with primigravida mothers $(8,36)$. In opposite studies 85 conducted in Northern Ireland and Bangalore shows that multigravidas had low prenatal stress 86 and primigravida have significant association with perceived stress during pregnancy $(35,12)$. 87 Perceived stress is also high among mothers who initiate antenatal care after 16 weeks of 88 gestation (10). The study conducted in Ethiopia indicates that gestational age less than twelve 89 weeks or first trimester is positively associated with perceived stress during pregnancy (9). 90 Studies conducted in different parts of the world show that unplanned pregnancy is 91 significantly associated with perceived stress during pregnancy $(10,11)$.

92 During antenatal care follow up pregnant mothers are not scanned to diagnose stress and due 93 to this fact it's difficult to identify which women are stressed (12). To the investigator 94 knowledge, there is only a single study done in Ethiopia among pregnant mothers but it lacks 95 important variables. Those missed variables include psychosocial variables like social support, sexual abuse, women concern about husband, family support, husband financial and 97 emotional support. Additionally the prevalence and contributing factors of perceived stress 98 which is representative of all women of the antenatal period is not studied specifically in 99 study area. Therefore, this study aimed to address perceived stress in pregnant mothers by 100 adding some important variables.

101

102

103

104

105

106

107 


\section{Socio-demographic factors}

Age Educational status of mother/partner

Obstetric factors $\downarrow$

\section{Gravidity Parity}

Multiple pregnancies

Time of initiation of ANC

Number of ANC visit

Status of pregnancy

Gestational age

Danger sign counseling

Obstetric complications
Perceived stress
Social support

Sexual abuse

Concern about Husband worries

Physical abuse during pregnancy

Husband Financial and emotional support

Family support

123 Figure 1: Conceptual framework developed from literatures to assess perceived stress and

124 associated factors among pregnant mothers attending antenatal care at Arba Minch town

125 governmental health institutions, southern Ethiopia, $2020(7,8,9,10)$

126 Methods

\section{Study design and setting}

128 Institution based cross sectional study was conducted from March 16 to April 23, 2020. Arba

129 Minch town is the capital of Gamo zone, which is $435 \mathrm{~km}$ from Addis Ababa and about 275

$130 \mathrm{Km}$ from Hawassa. The town has a total population of more than 200,373, of which 50.2\%

131 are females (44). Arba Minch town has an altitude ranged from 1200-1300 meters above sea

132 level with an average annual temperature of 29.70C. Arba Minch town has rain fall of 700

$133 \mathrm{~mm}$ per annum (44). The town has 1 general hospital and 2 governmental health centers. 


\section{Sample size and sampling procedure}

135 Sample size was determined by using single population proportion (SPP) formula based on 136 the assumptions of $95 \%$ confidence level, $11.6 \%$ p-value (previous home study), $3 \%$ 137 marginal error and a 5\% contingency. Finally, total sample size was 461. In this study all 138 governmental health institutions that provide ANC service in Arba Minch town were 139 included. The total population for these health institutions from their previous average 140 monthly ANC client flows of at least for three months was considered. Based on proportional 141 allocation sample size was allocated for each health facility. Skip interval was determined for 142 each heath facility by dividing the estimated population by the respective sample size (i.e. $143 \mathrm{Kth}=\mathrm{N} / \mathrm{n}$ ). Hence, each participant was selected by systematic sampling with skip interval 144 of 2 at each institution. Using lottery method, 1 was selected and used as a starting number 145 based on their arrival order. Subsequently, every other mother was included until the desired 146 sample size was achieved. (Figure 2)

147

Arba Minch health center $\mathrm{N}=197 \mathrm{n}=115$ 
158 Figure 2: Schematic representation of sampling procedure to assess perceived stress and 159 associated factors among pregnant women attending antenatal care at Arba Minch town governmental health institutions, southern Ethiopia, 2020

\section{Measurement}

Data were collected by face to face interview by 3 female BSc midwives. Structured questionnaire was used to collect the data. It has five sections. It contains socio-demographic variables, obstetric variables, maternal social support questions, perceived stress scale questions and psychosocial variable. Perceived stress was measured with the perceived stress scale (PSS). PSS is a 7-item multiple-choice self-report psychological instrument for measuring the perception of stress. Each answer is scored 0 to 3 (13). Perceived stress scale is an instrument used to measure perception of stress. The questions were designed to tap the degree and frequency of stressful thoughts during previous one month. Social support was measured using Maternity Social Support Scale (MSSS) (47). Obstetric and psychosocial

171 variables was developed from different literatures $(9,10)$.

\section{Operational definition}

173 Perceived stress: perceived stress is the imbalance that a pregnant woman feels when she 174 cannot cope with demands, which is expressed both behaviorally and physiologically. 175 Perceived stress scale is scored by summing across all scale items. The total score ranges 176 from 0.0-21.0 with higher scores indicating women with more perceived stress symptoms. 177 The cutoff value for the stress limit was set at $15(9,13,14)$.

178 Social support: Social support is the accessible support for a pregnant woman through social 179 relationships with other people, groups, and the larger community. Social support was 180 classified into three categories; high social support (for scores 24-30), medium social support 181 (18-23) and low social support (below 18) (15).

\section{Statistical analysis}

184 The pre coded responses were entered into Epi data version 3.1 software and then it was 185 exported to SPSS version 25 for statistical analysis. The perceived stress and social support 
questions were computed using likert scale. The descriptive data were presented using frequency, tables, figures, mean and standard deviation. A binary logistic regression was used to identify the association of the independent variables with the dependent variable. Each variable which have p-value less than 0.25 was added to the final model to control the confounders. Variables which have a p-value $<0.05$ with $95 \%$ confidence interval in the final model were declared statistically significant. Hosmer and Lameshow goodness of fit test was conducted to test the model fitness and the model was adequate ( $\mathrm{p}=0.876)$. Multicollinearity was checked by using VIF and it was $<10$.

\section{Data quality control}

To maintain data quality and make further adjustment the questioner was pretested in Lante health center on 23 (5\%) pregnant mothers. Supervision was conducted by the supervisor and the principal investigator and on spot questionnaire was checked for completeness and further edition. Sudden observation of how data collectors administer the questions to the respondents was made. Each data collector checks the questionnaires for completeness before winding up their visit to each study participant.

\section{Ethical issues}

Ethical clearance was obtained from Institutional Research Ethics Review Board (IRB) of College of Medicine and Health Sciences, Arba Minch University with reference number of IRB/177/12. Written permission was obtained from Arbaminch University. Consent was obtained from medical directors and respective unit heads at each health institutions. Verbal consent was obtained from individual clients. Confidentiality was strictly maintained for each piece of information and the interview was conducted in strict private place.

\section{Results}

\section{Socio-demographic Characteristics}

A total of 451 pregnant mothers were participated in this study giving a response rate of $98.04 \%$. The mean (mean $\pm \mathrm{SD}$ ) age of the respondents was $27 \pm 8$ years. Among the total participants, 186 (41.2\%) of mothers attended secondary school and above. About 205 $(45.5 \%)$ of the women were protestant in religion. Nearly half of the mothers 220 (48.8\%) were Gamo in ethnicity and 407 (90.24\%) of the mothers were married. With regard to 
215 occupational status housewife takes larger proportion 211 (46.8\%). The majority 357 $216(79.2 \%)$ of the mothers were urban residents. About $229(50.8 \%)$ of husbands attended 217 secondary school and above, and $173(38.4 \%)$ of husbands were government employee 218 (Table 1).

219 Table 1: Socio-demographic characteristics of pregnant women attending antenatal care unit 220 of Arba Minch town governmental health institutions, southern Ethiopia, 2020, $(n=451)$

\begin{tabular}{|c|c|c|c|}
\hline Variable & Category & Frequency & Percent \% \\
\hline \multirow[t]{3}{*}{ Age } & $\leq 24$ years & 157 & 34.8 \\
\hline & $25-34$ years & 216 & 47.9 \\
\hline & $\geq 35$ years & 78 & 17.3 \\
\hline \multirow[t]{4}{*}{ Educational status of mother } & Can't read and write & 120 & 26.6 \\
\hline & Can read and write & 91 & 20.2 \\
\hline & Primary school & 54 & 12 \\
\hline & Secondary and above & 186 & 41.2 \\
\hline \multirow[t]{5}{*}{ Religion of the mother } & Protestant & 205 & 45.5 \\
\hline & Orthodox & 193 & 42.8 \\
\hline & Muslim & 40 & 8.9 \\
\hline & Catholic & 12 & 2.7 \\
\hline & Wakefeta & 1 & 0.2 \\
\hline \multirow[t]{7}{*}{ Ethnicity of the mother } & Gamo & 220 & 48.8 \\
\hline & Gofa & 57 & 12.64 \\
\hline & Wolaita & 65 & 14.4 \\
\hline & Konso & 39 & 8.66 \\
\hline & Amhara & 41 & 9.1 \\
\hline & Oromo & 27 & 6.0 \\
\hline & Tigre & 2 & 0.4 \\
\hline \multirow[t]{4}{*}{ Marital status } & Married & 407 & 90.3 \\
\hline & Single & 33 & 7.3 \\
\hline & Divorced & 5 & 1.1 \\
\hline & Widowed & 6 & 1.3 \\
\hline \multirow{7}{*}{$\begin{array}{l}\text { Occupational status of the } \\
\text { mothers }\end{array}$} & Housewife & 211 & 46.8 \\
\hline & Merchant & 54 & 12.0 \\
\hline & Government employee & 86 & 19.1 \\
\hline & Farmer & 10 & 2.2 \\
\hline & Laborer & 12 & 2.7 \\
\hline & Student & 74 & 16.3 \\
\hline & Others (private) & 4 & 0.9 \\
\hline \multirow[t]{2}{*}{ Residence of mother } & Urban & 357 & 79.2 \\
\hline & Rural & 94 & 20.8 \\
\hline \multirow{3}{*}{$\begin{array}{l}\text { Educational status of the } \\
\text { father }\end{array}$} & can't read and write & 32 & 7.1 \\
\hline & can read and write & 145 & 32.1 \\
\hline & Primary school & 45 & 10 \\
\hline
\end{tabular}




\begin{tabular}{llll}
\hline & Secondary and above & 229 & 50.8 \\
\hline Occupational status of the & Farmer & 59 & 13 \\
father & Merchant & 86 & 19.1 \\
& Government employee & 173 & 38.4 \\
& Student & 18 & 4.0 \\
& Laborer & 103 & 22.8 \\
& Others (driver, private) & 12 & 2.7 \\
\hline Monthly income & $0-500$ & 25 & 5.5 \\
& $501-1000$ & 33 & 7.3 \\
& $1001-1500$ & 57 & 12.6 \\
& $1501-2000$ & 91 & 20.3 \\
& $>2000$ & 245 & 54.3 \\
\hline
\end{tabular}

\section{Obstetric factors}

222 From the total pregnant mothers participated in this study $284(63 \%)$ of them were 223 multigravidas. Among the respondents 209 (46.3\%) of them were nulliparous. About 262

$224(58.1 \%)$ of the mothers initiate antenatal care follow up before 16 weeks of gestation and 306 $225(67.8 \%)$ of pregnancies were planned. The mean gestational age of the mothers was $(23 \pm 8)$ 226 weeks. Majority 420 (93.1\%) of the pregnancies were singleton pregnancies. During current 227 pregnancy or previous pregnancy, 338 (74.9\%) of the study subjects reported that they 228 doesn't face any type of complication. Among the participants $429(95.1 \%)$ of them said they 229 were counseled on danger signs of pregnancy (Table 2).

230 Table 2: Obstetric characteristics of pregnant women attending antenatal care units of Arba 231 Minch town governmental health institutions, southern Ethiopia, $2020(n=451)$

\begin{tabular}{llll}
\hline Variable & Category & Frequency & Percentage (\%) \\
\hline Gravida & Primigravida & 136 & 30.2 \\
& Multigravida & 284 & 63.0 \\
\multirow{4}{*}{ Para } & Grand multigravida & 31 & 6.8 \\
& Nulliparous & 209 & 46.3 \\
\multirow{5}{*}{ Time of ANC initiation } & Primiparous & 95 & 21.1 \\
& Multipara & 147 & 32.6 \\
Gestational age & Before 16 weeks & 262 & 58.1 \\
& After 16 weeks & 189 & 41.9 \\
\multirow{3}{*}{ Status of pregnancy } & First trimester & 55 & 12.2 \\
\multirow{4}{*}{ Multiple pregnancy } & Second trimester & 198 & 43.9 \\
& Third trimester & 198 & 43.9 \\
& Planned & 306 & 67.8 \\
\hline
\end{tabular}




\begin{tabular}{llll}
\hline & No & 420 & 93.1 \\
Mother faced & Yes & 113 & 25.1 \\
complications & No & 338 & 74.9 \\
Type of complications & Prolonged labor & 16 & 14.16 \\
faced by mothers & Heavy bleeding & 9 & 7.96 \\
& Retained placenta & 7 & 6.2 \\
& Abortion & 72 & 63.72 \\
& Still birth & 3 & 2.65 \\
& Child death & 5 & 4.42 \\
Counseled about danger & Cervical incompetence & 1 & 0.89 \\
signs & Yes & 429 & 95.1 \\
& No & 22 & 4.9 \\
\hline
\end{tabular}

233 Regarding number of antenatal care follow up or visit, from the total participants of this 234 study about $168(37.3 \%)$ of pregnant mothers were on first antenatal care visit during data 235 collection period (Figure 3).

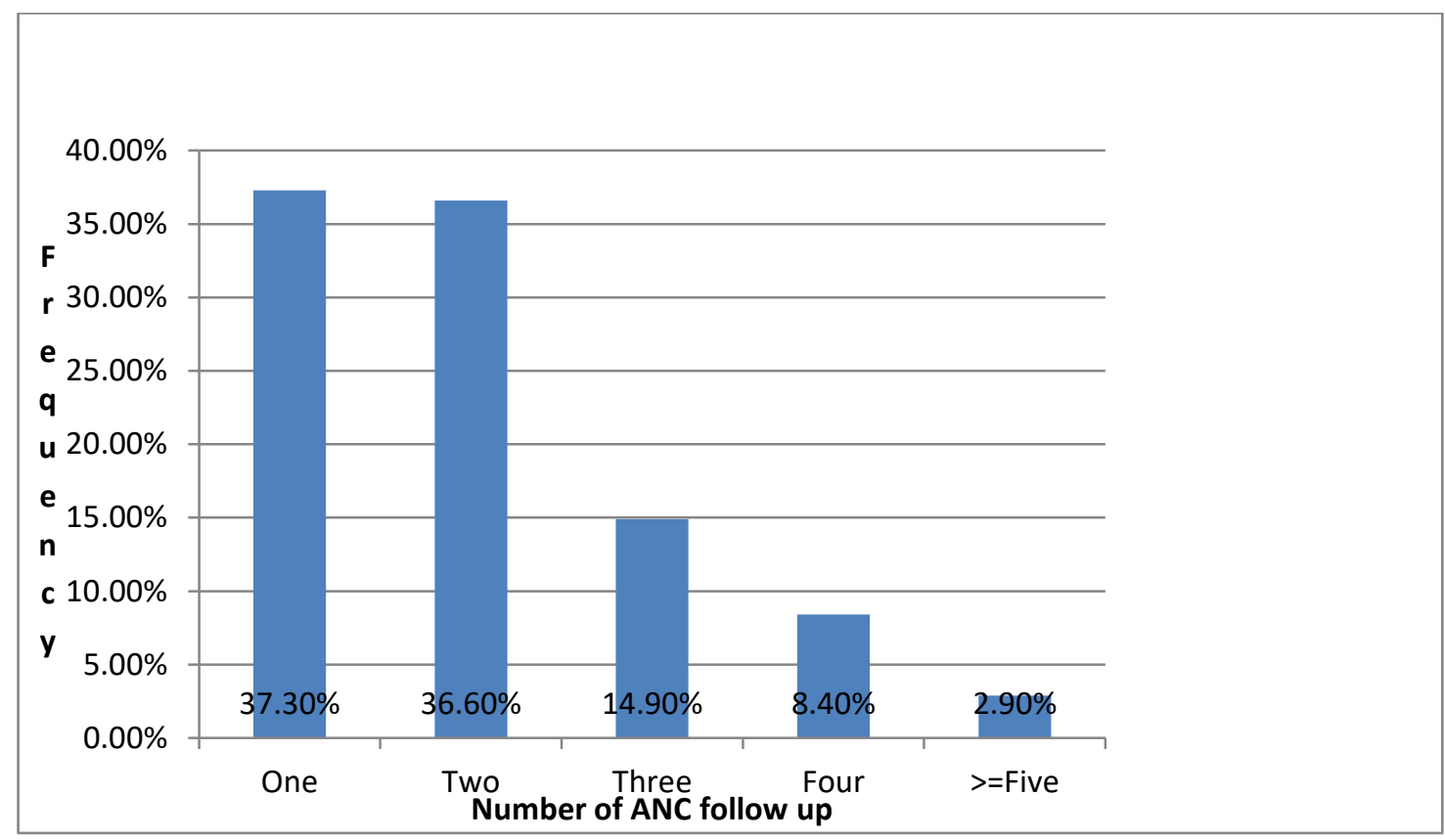

237 Figure 3: Number of ANC follow up among pregnant women attending antenatal care unit of 238 Arba Minch town governmental health institutions, southern Ethiopia, $2020(n=451)$

\section{Psychosocial factors}

\section{Maternal social support scale}


241 Among the respondents 313 (69.4\%) of the mothers have good friends who support them, $242367(81.4 \%)$ of the subjects had family always there for them and $403(89.4 \%)$ of the mothers 243 said their husband/partner helps them a lot. About $399(88.5 \%)$ the mothers reported they 244 have no conflict with their husband or partner and $391(86.7 \%)$ of the respondents said they 245 did not feel controlled by their husband/partner. The majority $386(85.6 \%)$ of the mothers, 246 feel loved by their husband or their partner. Regarding the maternal social support scale from 247 total pregnant mothers participated in this study $212(47 \%)$ of them has low maternal social 248 support (Figure 4).

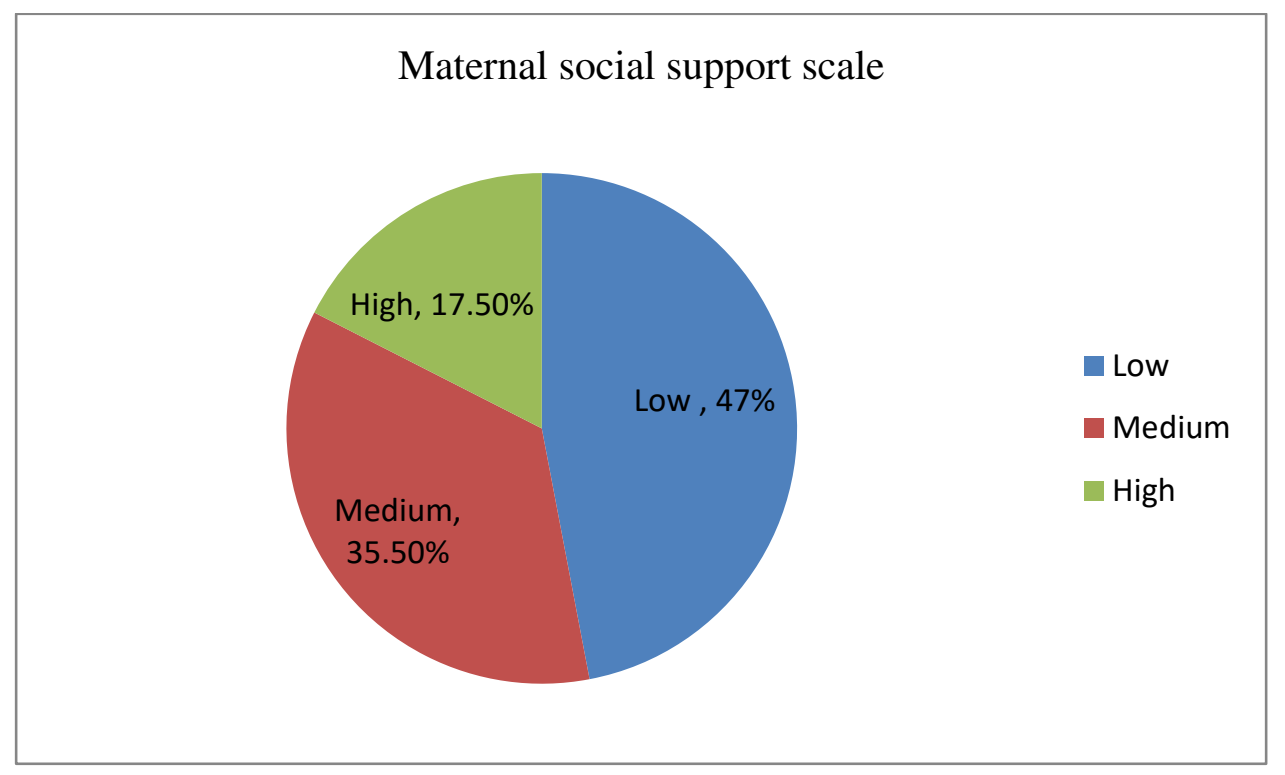

250 Figure 4: maternal social support scale result among pregnant women attending antenatal

251 care units of Arba Minch town governmental health institution, southern Ethiopia, 2020

$252 \quad(n=451)$

\section{Other psychosocial factors}

254 Among the total 451 pregnant mothers participated in this study $316(70.1 \%)$ of them said 255 they have no concern towards their husband worries. From those mothers who have a 256 concern toward their husband worries 51 (52.59\%) of them have concern about their 257 husbands health. About $386(85.6 \%)$ of mothers said their husbands provide an emotional 258 support during their pregnancy time. Among the total participants $390(86.5 \%)$ of mothers 259 said their husbands provide financial support during their pregnancy time. Majority 327 $260(72.5 \%)$ of mothers have family support at their pregnancy period (Table 3). 
261 Table 3: Psychosocial factors among pregnant women attending antenatal care units of Arba 262 Minch town governmental health institution, southern Ethiopia, $2020(n=451)$

\begin{tabular}{|c|c|c|c|}
\hline Variable & Category & Frequency & Percentage \\
\hline \multirow{2}{*}{$\begin{array}{l}\text { Concern towards husband } \\
\text { worries }\end{array}$} & Yes & 135 & 29.9 \\
\hline & No & 316 & 70.1 \\
\hline \multirow{3}{*}{$\begin{array}{l}\text { Reason for concern toward } \\
\text { husband worries }\end{array}$} & Fear of his health & 71 & 52.6 \\
\hline & Fear of losing his job & 51 & 37.8 \\
\hline & Others & 13 & 9.6 \\
\hline \multirow{2}{*}{$\begin{array}{l}\text { Husband emotional support } \\
\text { during pregnancy }\end{array}$} & Yes & 386 & 85.6 \\
\hline & No & 65 & 14.4 \\
\hline \multirow{2}{*}{$\begin{array}{l}\text { Husband financial support } \\
\text { during pregnancy }\end{array}$} & Yes & 390 & 86.5 \\
\hline & No & 61 & 13.5 \\
\hline \multirow{2}{*}{$\begin{array}{l}\text { Family support during } \\
\text { pregnancy }\end{array}$} & Yes & 327 & 72.5 \\
\hline & No & 124 & 27.5 \\
\hline
\end{tabular}

264 Abuse during pregnancy

265 Most $370(82 \%)$ of the mothers were not emotionally or physically abused by their partner or 266 someone important to them. In the last year, 397 (88\%) of the subjects said they were not hit, 267 slapped, kicked or otherwise physically hurt by someone; while the rest were hurt. From 268 those hurt last year many 46(85.2\%) of them were hurt by their husbands and the half 27 $269(50 \%)$ were hurt two times. Since pregnant, $427(94.7 \%)$ of mothers said they were not 270 slapped, kicked or otherwise hurt by someone, while the rest of them were hurt. Among those 271 hurt during pregnancy, highest number $20(83.3 \%)$ of them were hurt by their husbands and 272 the majority $16(66.7 \%)$ were hurt only one time. From those hurt during pregnancy threats 273 of abuse including use of weapon was the more $11(45.8 \%)$ frequent one. Within last year, 274 about $424(94 \%)$ of the pregnant mothers said they were not forced to have sexual activities 275 with anyone; while the rest were forced. From those forced to have sexual activities majority $27618(66.7 \%)$ were forced by their boyfriend. Among pregnant mothers participated in this 277 study $401(88.9 \%)$ of them doesn't afraid of their partner or anyone (Table 4). 
278 Table 4: Abuse among pregnant women attending antenatal care units of Arba Minch town

279 governmental health institution, southern Ethiopia, $2020(n=451)$

\begin{tabular}{|c|c|c|c|}
\hline Variable & Category & Frequency & Percentage \\
\hline \multirow{2}{*}{$\begin{array}{l}\text { Have you ever been emotionally or physically } \\
\text { abused by your partner or someone important to } \\
\text { you? }\end{array}$} & Yes & 81 & 18.0 \\
\hline & No & 370 & 82.0 \\
\hline \multirow{2}{*}{$\begin{array}{l}\text { Within the last year, have you been hit, slapped, } \\
\text { kicked or otherwise physically hurt by someone? }\end{array}$} & Yes & 54 & 12.0 \\
\hline & No & 397 & 88.0 \\
\hline \multirow{4}{*}{$\begin{array}{l}\text { If hit, slapped, kicked or hurt by someone last } \\
\text { year; by whom? }\end{array}$} & Husband & 46 & 85.2 \\
\hline & Ex-husband & 1 & 1.9 \\
\hline & Boyfriend & 6 & 11 \\
\hline & Stranger & 1 & 1.9 \\
\hline \multirow{5}{*}{$\begin{array}{l}\text { If hit, slapped, kicked or hurt by someone last } \\
\text { year; total number of times? }\end{array}$} & One time & 12 & 22.2 \\
\hline & Two times & 27 & 50.0 \\
\hline & Three times & 8 & 14.8 \\
\hline & Four times & 6 & 11.1 \\
\hline & Five times & 1 & 1.9 \\
\hline \multirow{5}{*}{$\begin{array}{l}\text { Since you've been pregnant, have you been } \\
\text { slapped, kicked or otherwise physically hurt by } \\
\text { Someone? } \\
\text { If slapped, kicked or hurt by someone during } \\
\text { pregnancy; by whom? }\end{array}$} & Yes & 24 & 5.3 \\
\hline & No & 427 & 94.7 \\
\hline & Husband & 20 & 83.3 \\
\hline & Boyfriend & 3 & 12.5 \\
\hline & Stranger & 1 & 4.2 \\
\hline \multirow{3}{*}{$\begin{array}{l}\text { If slapped, kicked or hurt by someone during } \\
\text { pregnancy; total number of times? }\end{array}$} & One time & 16 & 66.7 \\
\hline & Two times & 7 & 29.1 \\
\hline & Three times & 1 & 4.2 \\
\hline \multirow[t]{5}{*}{$\begin{array}{l}\text { If slapped, kicked or hurt by someone during } \\
\text { pregnancy; score incident? }\end{array}$} & $\begin{array}{l}\text { Threats of } \\
\text { abuse }\end{array}$ & 11 & 45.8 \\
\hline & Slapping & 9 & 37.5 \\
\hline & Punching, & 2 & 8.3 \\
\hline & Beating up & 1 & 4.2 \\
\hline & Head injury & 1 & 4.2 \\
\hline \multirow{2}{*}{$\begin{array}{l}\text { Within the last year, has anyone forced you to } \\
\text { have sexual activities? }\end{array}$} & Yes & 27 & 6.0 \\
\hline & No & 424 & 94.0 \\
\hline \multirow[t]{2}{*}{ If forced for sexual activities by whom? } & Husband & 9 & 33.3 \\
\hline & Boyfriend & 18 & 66.7 \\
\hline
\end{tabular}




\begin{tabular}{llll}
\hline If forced for sexual activities total number of & One time & 12 & 44.45 \\
times & Two times & 12 & 44.45 \\
& Three times & 1 & 3.7 \\
& Five times & 2 & 7.4 \\
Are you afraid of your partner or anyone? & Yes & 50 & 11.1 \\
& No & 401 & 88.9 \\
\hline
\end{tabular}

\section{Perceived stress}

281 The mean value of perceived stress among pregnant women was $12.64 \pm 2.8$ (mean \pm SD).

282 Overall, the prevalence of perceived stress among pregnant women attending antenatal care

283 unit of Arba Minch town governmental health institutions was $23.1 \%$ (95\% CI; 19.16-

$28426.96 \%$ ) ( Figure 5). From the total participants $379(84 \%)$ of the mothers were upset

285 because of something that happened unexpectedly in the last month, 339 (75.2\%) of the

286 pregnant mothers were unable to control important things in their life during the last month

287 and $392(86.9 \%)$ of the subjects have felt nervous and stressed in the last month. About 401

$288(88.9 \%)$ of the mothers felt that they are confident about their ability to handle their personal

289 problems and the majority 406 (90\%) felt that things were going their way. The majority 424

290 (94\%) of the participants were able to control irritations in their life during the last month. In

291 the last month $331(73.4 \%)$ of the subjects were angered because of things that were outside

292 of their control.

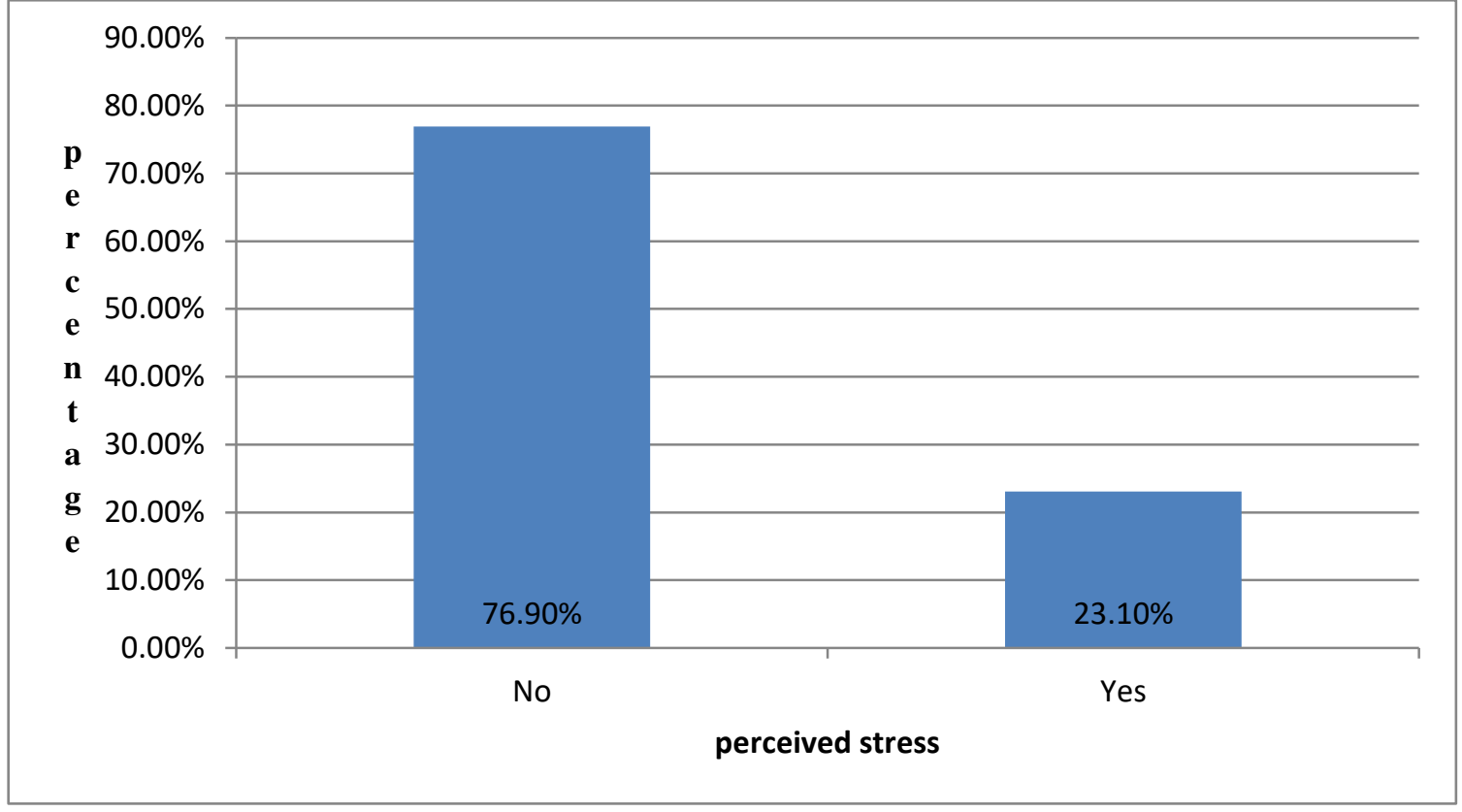


294 Figure 3: Perceived stress scale among pregnant women attending antenatal care units of 295 Arba Minch town governmental health institution, southern Ethiopia, $2020(n=451)$

\section{Factors associated with perceived stress during pregnancy}

297 The association between perceived stress and its associated factors among pregnant mothers 298 was analyzed using binary logistic regression. All factors which have a p- value <0.25 in 299 bivariable analysis were considered to multivariable logistic regression model.

300 Hence, educational status of the father, gravidity, time of ANC initiation, gestational age, 301 status of pregnancy (weather planned or unplanned), facing health problem, maternal social 302 support during pregnancy, concern towards husband worries, husband emotional support 303 during pregnancy, husband financial support during pregnancy and family support during 304 pregnancy were included into multivariable analysis. But only, gravidity, time of ANC 305 initiation, gestational age and status of pregnancy were found to be statistically significant at 306 p- value $<0.05$.

307 The odds of developing perceived stress during pregnancy was 3.95 times higher among 308 Pregnant women who were multigravida as compared to primigravida woman (AOR=3.95, $30995 \% \mathrm{CI} ; 1.94-8.02)$. The odds of having perceived stress was 2.05 times higher among 310 pregnant mothers who initiate antenatal care before 16 weeks than those mothers who initiate 311 antenatal care after 16 weeks of gestation $(\mathrm{AOR}=2.05,95 \% \mathrm{CI} ; 1.18-3.57)$. Those mothers 312 with in first trimester of pregnancy had perceived stress 3.03 times higher than mothers with 313 in third trimester $(\mathrm{AOR}=3.03,95 \% \mathrm{CI} ; 1.34-6.85)$. The likelihood of having perceived 314 stress was about 4.32 times higher for mothers who has unplanned pregnancy $(\mathrm{AOR}=4.32$, $31595 \% \mathrm{CI} ; 2.55-7.31$ ) as compared to those mothers whose pregnancy was planned (Table 5).

316 Table 5: Bivariable and multivariable logistic regression model predicting the likelihood of 317 perceived stress among pregnant women attending antenatal care unit at Arba Minch town 318 governmental health institutions, southern Ethiopia, $2020(n=451)$

\begin{tabular}{lllll}
\hline Variable & Perceived stress & COR $(95 \%$ CI $)$ & AOR (95\% CI) & Pvalue \\
& Yes & No & & \\
\hline
\end{tabular}




$\begin{array}{lllll}\text { Can't read and write } & 12(11.4 \%) & 20(5.8 \%) & 1.93(0.89-4.21) & 2.02(0.80-5.11) \\ \text { Can read and write } & 29(28 \%) & 116(33.4 \%) & 0.91(0.56-1.5) & 0.87(0.47-1.60) \\ \text { Primary school } & 15(14.4 \%) & 30(8.6 \%) & 0.32(0.09-1.09) & 1.85(0.81-4.24) \\ \text { Secondary\& above } & 48(46.2 \%) & 181(52.2 \%) & 1 & 1\end{array}$

\section{Gravida}

\begin{tabular}{lrllll} 
Multigravida & $86(82.7 \%)$ & $229(66 \%)$ & $2.46(1.41-4.28)$ & $3.95(1.94-8.02)^{*}$ & $<0.001$ \\
Primigravida & $18(17.3 \%)$ & $118(34 \%)$ & 1 & 1 & \\
\multicolumn{2}{l}{ Time of ANC initiation } & & & & \\
Before 16 weeks & $75(72.1 \%)$ & $187(53.9 \%)$ & $2.21(1.37-3.57)$ & $2.05(1.18-3.57)^{*}$ & 0.011 \\
After 16 weeks & $29(27.9 \%)$ & $160(46.1 \%)$ & 1 & 1
\end{tabular}

\section{Gestational age}

Second trimester

Third trimester

\section{Status of pregnancy}

Unplanned

$$
65(62.5 \%) \quad 80(23 \%) \quad 5.56(3.48-8.89)
$$

Planned
First trimester

$$
\begin{array}{lll}
21(20.2 \%) & 34(9.8 \%) & 2.44(1.28-4.65) \\
43(41.3 \%) & 155(44.7 \%) & 1.09(0.67-1.77) \\
40(38.5 \%) & 158(45.5 \%) & 1
\end{array}
$$

\section{Health problems during}

pregnancy

Yes

$$
\begin{array}{lll}
21(20.2 \%) & 92(26.5 \%) & 0.70(0.41-1.19) \\
83(79.8 \%) & 255(73.5 \%) & 1
\end{array}
$$

\section{Social support}

Low

$$
63(60.6 \%) \quad 149(42.9 \%) \quad 2.91(1.41-6.02)
$$

Medium

$$
31(29.8 \%) \quad 129(37.2 \%) \quad 1.65(0.76-3.58)
$$

High

\section{Concern toward husband worries}

Yes

$$
40(38.5 \%) \quad 95(27.4 \%) \quad 1.65(1.04-2.62)
$$

3.03(1.34-6.85)* 0.008

$1.25(0.71-2.22)$

1

$$
4.32(2.55-7.31)^{*} \quad<0.001
$$

1

$0.57(0.30-1.08)$

1

$1.74(0.73-4.10)$

$1.29(0.54-3.10)$

1

$1.52(0.88-2.64)$ 


\section{Husband emotional support}

$\begin{array}{lllll}\text { No } & 25(24 \%) & 40(11.5 \%) & 2.42(1.39-4.24) & 3.98(0.392-4.60) \\ \text { Yes } & 79(76 \%) & 307(88.5 \%) & 1 & 1\end{array}$

\section{Husband financial support}

$\begin{array}{lllll}\text { No } & 24(23 \%) & 37(10.7 \%) & 2.51(1.42-4.44) & 0.34(0.03-3.67) \\ \text { Yes } & 80(77 \%) & 310(89.3 \%) & 1\end{array}$

\section{Family support}

\begin{tabular}{|c|c|c|c|c|}
\hline No & $40(38.5 \%)$ & $84(24.2 \%)$ & $1.95(1.22-3.11)$ & $1.04(0.57-1.88)$ \\
\hline Yes & $64(61.5 \%)$ & $263(75.6 \%)$ & 1 & 1 \\
\hline
\end{tabular}

\section{DISCUSSION}

320 The magnitude of perceived stress among pregnant women attending antenatal care unit of 321 Arba Minch town governmental health institutions was found to be $23.1 \%$ (95\% CI; 19.16322 26.96\%). This finding was higher than the study conducted in Bale zone Ethiopia which 323 found that $11.4 \%$ of mothers had perceived stress during their pregnancy (9). The possible 324 explanation for this difference might be due to difference in age group among each study 325 respondents and educational status in which majority of this study participants were not 326 educated while compared with the Bale study. The discrepancy can also be as a result of 327 difference in geographical factors.

328 This study finding was also higher than the studies carried out in Iran $12.4 \%$, United states of 329 America 6\%, Ardabil Iran 7.33\% and Canada 17.2\% (16-19). The reason for this difference 330 might be the socio-cultural difference, geographical area, economic status and difference in 331 life standard across the countries. The inconsistency can also be due to small sample size 332 especially for studies conducted in Iran in which only 200 mothers participated in the study. 333 The other possible reason for this difference may be due to lack of an ability to deal with 334 stressful events between current study participants and those studies.

335 Inversely, the finding in this study was lower than studies conducted in Saudi Arabia 33.4\%, 336 Ghana 50\%, Democratic republic of Congo 57.1\%, Nepal 34\%, America 28\% and Ghana 
$33728.6 \%(20-25)$. The discrepancy can be explained as due to difference in socio cultural 338 status, study period and study setting. The other possible reason might be in Ethiopia the 339 community widely supports women during pregnancy and this may reduce stress among 340 pregnant women.

341 In current study, multigravida women were more likely to have perceived stress than those 342 who were primigravida. This finding is supported by study findings conducted in Bale zone 343 Ethiopia, and united states of America $(9,12)$. This similarity may be due to the same socio344 cultural and living standard across the country especially with the study conducted in 345 Ethiopia. This finding is opposed with studies conducted in Northern Ireland and Bangalore 346 which show that multigravidas had low prenatal stress and primigravida have significant 347 association with perceived stress during pregnancy $(8,26)$. The possible reason for this 348 discrepancy might be due to burden applied to multigravida mothers.

349 This burden can occur due to low economic status and taking responsibility of raising a child. 350 Mothers with previous bad obstetric history may also be worried towards current pregnancy 351 and this may lead them to stress too.

352 In the present study, pregnant women who initiate antenatal care before 16 weeks of 353 gestation had significant association with perceived stress than those mothers who initiate 354 antenatal care after 16 weeks of gestation. This finding is in contrary with the study 355 employed in China which states that late initiation of antenatal care is significantly associated 356 with higher level of perceived stress (11). The possible explanation for this difference might 357 be pregnant mothers in this study who have the feeling of stress may seek health care early 358 than those who have normal status. Women's in early period of pregnancy face different 359 physiological changes and this change may expose them to stress. To alleviate this feeling of 360 stress pregnant mothers may seek health care early and diagnosed with perceived stress. The 361 other reason for this discrepancy might be pregnant women with previous obstetric 362 complications may be highly concerned about current pregnancy status and this can lead 363 them to have stress. So, as known if the women has previous pregnancy problem there is a 364 high chance that she goes to health institution early and she may be diagnosed with stress 365 before sixteen weeks of gestation. 
According to this study finding, pregnant women with in first trimester of gestation had

367 perceived stress when compared with pregnant women with third trimester of gestation. This

368 finding is in line with the study carried out at Bale zone of Ethiopia (9).

369 This study finding shows that perceived stress during pregnancy was higher for mothers 370 whose pregnancies were unplanned than mothers whom pregnancies were planned. This

371 finding is supported by studies conducted in India and China (10,11). The consistency may 372 be due to dilemma or worrying about what to do with unplanned pregnancy among all 373 pregnant women regardless of the country they are living in. The similarity might also be as a 374 result of lower socioeconomic status which makes mothers difficult to cope up with 375 pregnancy and inability of raising a child with limited resource. Additionally lack of social 376 support during pregnancy especially for unplanned one may lead the mother to be isolated 377 and this may result in stress. Stress may also develop among mothers who have lack of 378 interest in accepting unplanned pregnancy.

379 Stress during pregnancy might also occur among women with unplanned pregnancy due to 380 their occupational status since the pregnancy of majority of students were unplanned and 381 with increasing maternal age the chance of occurrence of unplanned pregnancy is higher and 382 this can also leads stress during pregnancy.

\section{Strengths of the study}

384 Many variables were addressed and assessed.

\section{Limitations of the study}

386 This study was an institution-based study; hence findings may not reflect the stress of all 387 pregnant women in the community. Social desirability bias could also be a concern. The 388 cross-sectional study could not help the researcher to establish cause - effect relationship.

\section{Conclusion and Recommendations}

390 The magnitude of perceived Stress during pregnancy was high among pregnant women 391 attending antenatal care in the study area. Multigravidas, antenatal care initiation before 16 392 weeks of gestation, first trimester pregnancy and unplanned pregnancy expose the mother to 393 perceived stress during pregnancy. Pregnant women's should discuss with their partner or 394 their family members and health care professionals on their emotional status. Health care 
395 professionals should assess feeling of multigravida women and provide adequate information 396 on their pregnancy, provide emotional support regardless of ANC initiation, encourage 397 mothers with early pregnancy and advise pregnant mothers. Town health bureau should 398 strengthen health extension workers to counsel and advice the mothers about stress during 399 pregnancy, arrange community based interventional strategies and provide family planning 400 methods for those in need,. Health care managers and policy makers should strengthen 401 policies and strategies focused on women education, use this study as an input to carry out 402 further investigation and make the problem get addressed. Educators should use the findings 403 in teaching learning process and researchers should conduct mixed study to identify different 404 factors like social support.

\section{List of Abbreviations}

406 ANC: Antenatal Care

407 IRB: Institutional Research Ethics Review Board

408 MSSS: Maternity Social Support Scale

409 PSS: Perceived Stress Scale

410 WHO: World Health Organization

\section{Competing Interest}

412 The authors have declared that no competing interests exist.

\section{Acknowledgement}

414 We would like to give our heart felt gratitude to Arba Minch town governmental health 415 institutions for providing us necessary information. We acknowledge Arba Minch 416 University College of Medicine and Health Science, school of Nursing for giving us a 417 chance to develop this research paper. Our deepest gratitude also goes to the study 418 participants, data collectors and for all who ever assisted us in developing this research 419 paper.

\section{Authors' contributions}


421 AD: Developed design, coordinated the study, performed statistical analysis and sequence 422 alignment, and drafted the manuscript. WE: Participated on Design development, performed 423 statistical analysis, participated drafting the manuscript. GE: Coordinated the study, 424 developed design, statistical analysis and participated manuscript draft development. WA: 425 Coordinated the study, entered data, participated in developing the document KB: 426 Participated on Design development, entered data and participated manuscript draft 427 development. TW: Coordinated the study, entered data, participated in developing the 428 document. All these authors read and approved the final manuscript.

\section{Authors' Information}

$430{ }^{1}$ Department of Midwifery, Arsi University College of Medicine and Health Sciences, 431 Oromia, Ethiopia

$432{ }^{2}$ School of Nursing, Arba Minch University College of Medicine and Health Sciences, 433 Arba Minch, Southern Ethiopia

$434{ }^{3}$ Department of Nursing, Mettu University Faculty of Public Health and Medical Science, 435 Mettu, western Ethiopia.

\section{References}

438 1. Fink G. Stress: Definition and history. Stress Sci. 2010 Jan 1;3-9.

$4392 . \quad$ Ruiz RJ, Fullerton JT. The measurement of stress in pregnancy. Nurs Health Sci.

4401999 Mar;1(1):19-25.

441 3. Gul F, Sherin AL, Jabeen M, Khan SA. Association of stress with anxiety and 442 depression during pregnancy. JPMA The Journal of the Pakistan Medical Association. $443 \quad$ 2017;67(12):1803-8.

444 4. Mental Health Foundation. Stress and pregnancy (prenatal and perinatal) |

445 Introduction [Internet]. Encyclopedia on Early Childhood Development. 2018 [cited 2019

446 Nov 28]. Available from: http://www.child-encyclopedia.com/stress-and-pregnancy-prenatal447 and-perinatal/introduction

448 5. Hobel CJ, Goldstein A, Barrett ES. Psychosocial stress and pregnancy outcome. Clin 449 Obstet Gynecol. 2008;55(2):333-48. 
450 6. Susan Cha, Saba W. Masho. Preterm Birth and Stressful Life Events | IntechOpen 451 [Internet]. 2013 [cited 2019 Nov 28]. Available from:

452 https://www.intechopen.com/books/preterm-birth/preterm-birth-and-stressful-life-events

453 7. Staneva A, Bogossian F, Pritchard M, Wittkowski A. The effects of maternal 454 depression, anxiety, and perceived stress during pregnancy on preterm birth: A systematic 455 review. Women and Birth. 2015 Sep 1;28(3):179-93.

456 8. Lynn FA, Alderdice FA, Crealey GE, McElnay JC. Associations between maternal 457 characteristics and pregnancy-related stress among low-risk mothers: An observational cross458 sectional study. International Journal of Nursing Studies. 2011 May 1;48(5):620-7.

459 9. Engidaw N, Mekonnen A, Amogne F. Perceived stress and its associated factors 460 among pregnant women in Bale zone Hospitals, Southeast Ethiopia: a cross-sectional study. 461 BMC Research Notes. 2019 Dec 1;12(356).

462 10. Vijayaselvi R, Beck MM, Abraham A, Kurian S, Regi A, Rebekah G. Risk Factors 463 for Stress During Antenatal Period Among Pregnant Women in Tertiary Care Hospital of 464 Southern India. J Clin Diagn Res. 2015 Oct;9(10):QC01-05.

465 11. Lau Y, Yin L. Maternal, obstetric variables, perceived stress and health-related 466 quality of life among pregnant women in Macao, China. Midwifery. 2011 Oct 1;27(5):66846773.

468 12. Pais M, Pai MV. Stress among pregnant women: A systematic review. Journal of 469 Clinical and Diagnostic Research. 2018 May 1;12(5):LE01-4.

470 13. Cohen S, Kamarck T, Mermelstein R. A global measure of perceived stress. Journal 471 of Health and Social Behavior. 1994;235-83.

472 14. Mekonnen A, Amogne F, Kassahun C. Risk Factors of Hyperemesis Gravidarum 473 among Pregnant Women in Bale Zone Hospitals, Southeast Ethiopia: Unmatched Case474 Control Study. Clinics in Mother and Child Health. 2018 Jan 1;15.

475 15. Webster J, Linnane JW, Dibley LM, Hinson JK, Starrenburg SE, Roberts JA. 476 Measuring social support in pregnancy: can it be simple and meaningful? Birth. 2000 477 Jun;27(2):97-101.

478 16. Shishehgar S, Dolatian M, Majd H, Bakhtiary M. Socioeconomic Status and Stress 479 Rate during Pregnancy in Iran. Global Journal of Health Science. 2014 Apr 22;6(4):p254.

480 17. Woods SM, Melville JL, Guo Y, Fan M-Y, Gavin A. Psychosocial stress during 481 pregnancy. Am J Obstet Gynecol. 2010 Jan;202(1):61.e1-7. 
482 18. Mirghafourvand M, Mohammad-Alizadeh S, Malakouti J. Perceived Stress and its

483 Relationship With Social Support in Pregnant Women Referring to Health Centers of

484 Ardabil, Iran. 2019 Oct 8;6:505-10.

485 19. Rieger K, Heaman M. Factors Associated With High Levels of Perceived Prenatal

486 Stress Among Inner-City Women. Journal of Obstetric Gynecologic \& Neonatal Nursing.

$487 \quad 2016$ Mar 1;45.

488 20. Ahmed AE, Albalawi AN, Alshehri AA, AlBlaihed RM, Alsalamah MA. Stress and

489 its predictors in pregnant women: a study in Saudi Arabia. Psychol Res Behav Manag.

$490 \quad 2017 ; 10: 97-102$.

491 21. Ae-Ngibise K, Wylie B, Boamah E, Jack D, Oppong F, Chillrud S, et al. Prenatal

492 maternal stress and birth outcomes in rural Ghana: sex-specific associations. BMC Pregnancy

493 and Childbirth. 2019 Dec 1;19.

494 22. Tandu-Umba B, Dedetemo DK, Mananga GL. Maternal Stress and Pregnancy

495 Outcomes. Open Journal of Obstetrics and Gynecology. 2014 May 12;4(7):361-70.

496 23. Pantha S. Prevalence of Stress among Pregnant Women Attending Antenatal Care in

497 a Tertiary Maternity Hospital in Kathmandu. Journal of Women's Health Care. 2014 Jan

$498 \quad 1 ; 03(5)$.

499 24. Gariepy AM, Lundsberg LS, Miller D, Stanwood NL, Yonkers KA. Are pregnancy

500 planning and pregnancy timing associated with maternal psychiatric illness, psychological

501 distress and support during pregnancy? Journal of Affective Disorders. 2016 Nov 15;205:87-

50294.

503 25. Boakye-Yiadom A, Shittu S, Dutt J, Dapare P, Abass A. Perceived stress and anxiety 504 among Ghanaian pregnant women. Journal of Medical and Biomedical Sciences. 2015 Dec $50517 ; 4: 29$.

$50626 . \quad$ S RH, C RPT, Awati M. Impact of maternal stress on outcome of new born.

507 International Journal of Contemporary Pediatrics. 2018 Apr 20;5(3):928-32.

508

509 


\begin{tabular}{|l|l|l|}
\hline \multicolumn{1}{|l|}{ Socio-demographic factors } \\
\hline Residence \\
\hline Obstetric factors
\end{tabular}

Figure 1

Conceptual framework developed from literatures to assess perceived stress and associated factors among pregnant mothers attending antenatal care at Arba Minch town governmental health institutions, southern Ethiopia, $2020(7,8,9,10)$ 


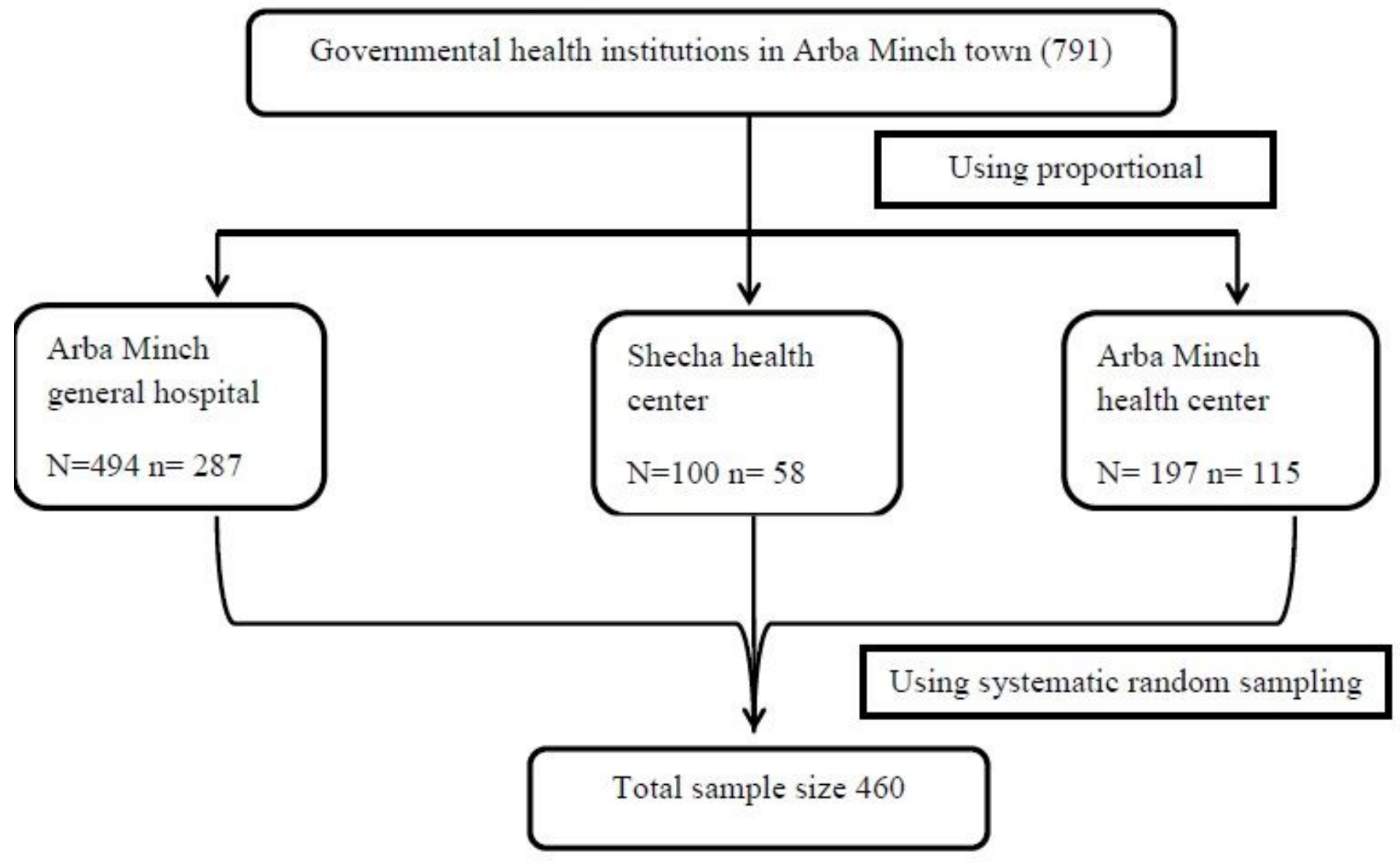

Figure 2

Schematic representation of sampling procedure to assess perceived stress and associated factors among pregnant women attending antenatal care at Arba Minch town governmental health institutions, southern Ethiopia, 2020

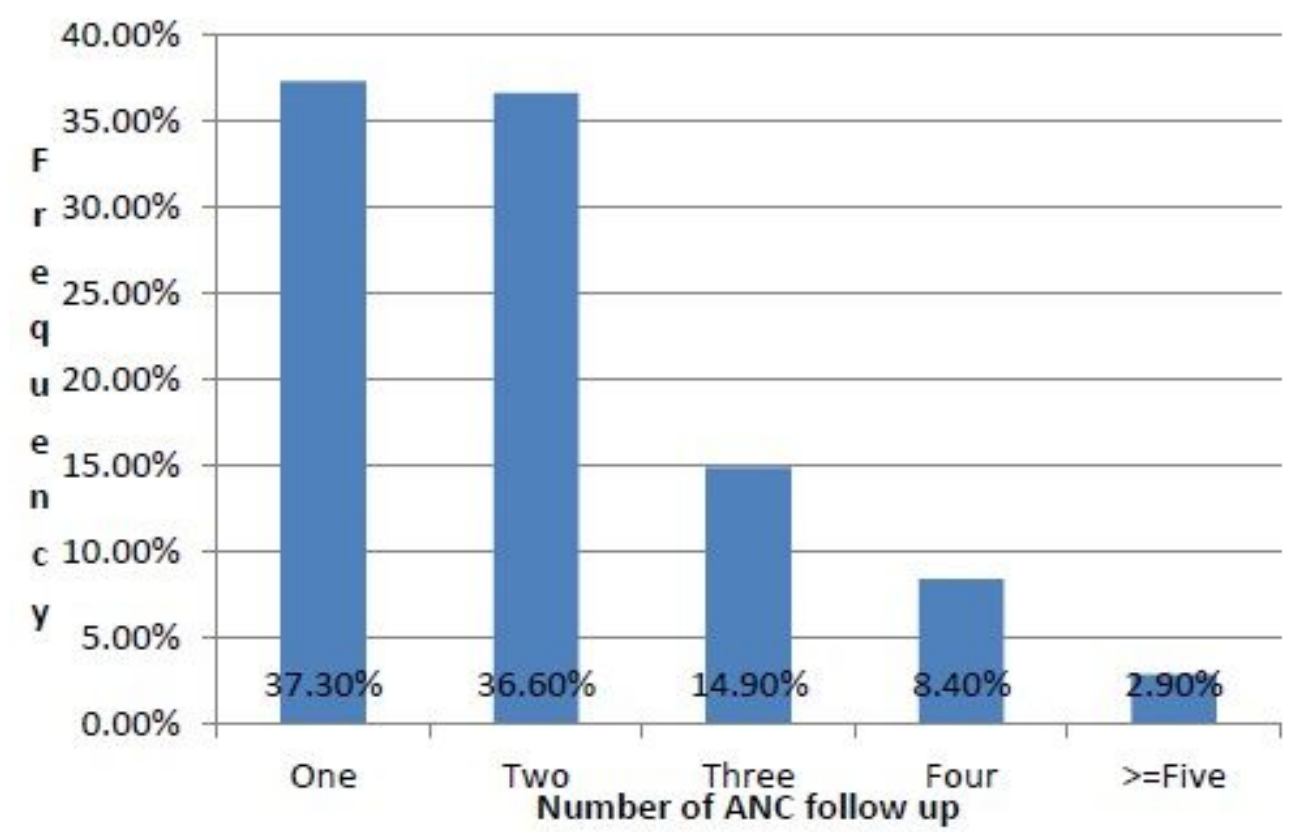




\section{Figure 3}

Number of ANC follow up among pregnant women attending antenatal care unit of Arba Minch town governmental health institutions, southern Ethiopia, 2020 ( $n=451)$

\section{Maternal social support scale}

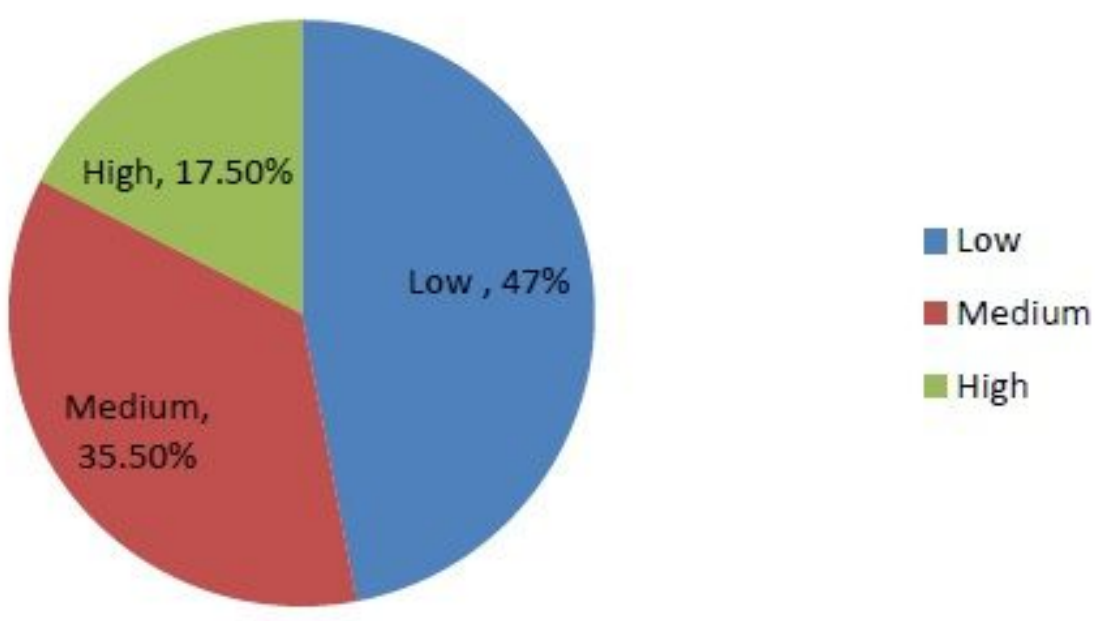

Figure 4

maternal social support scale result among pregnant women attending antenatal care units of Arba Minch town governmental health institution, southern Ethiopia, $2020(n=451)$

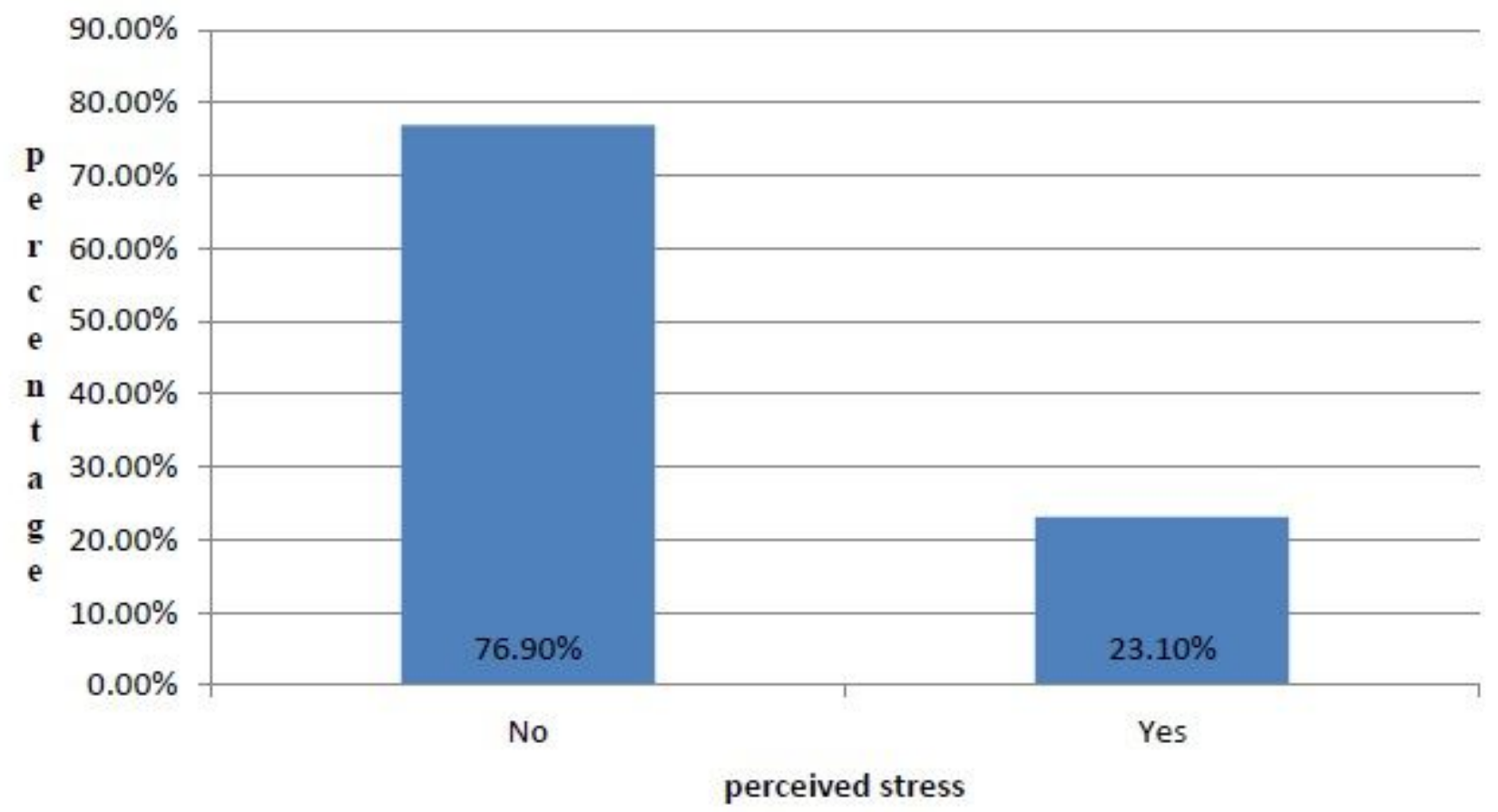

Figure 5 
Perceived stress scale among pregnant women attending antenatal care units of Arba Minch town governmental health institution, southern Ethiopia, $2020(n=451)$ 